\title{
Dental Antibiotic Prophylaxis and Prosthetic Joint Infections: A Narrative Review
}

\author{
NS Jayalakshmi ${ }^{1 *}$, Sheetal Saklecha ${ }^{1}$ and NS Harshavardhana ${ }^{2}$ \\ ${ }^{1}$ Santosh Dental Care, Bengaluru, India \\ ${ }^{2}$ Dumfries \& Galloway Royal Infirmary, Dumfries; United Kingdom
}

\begin{abstract}
*Corresponding author: NS Jayalakshmi MDS, Santosh Dental Care, Bengaluru, India, Email id: santoshdentalcare@gmail.com.
\end{abstract}

Received Date: February 20, 2021

Published Date: March 09, 2021

\begin{abstract}
Prosthetic joint infection (PJI) is the 3rd most common cause of revision in total hip arthroplasty (THA) and the most common cause of revision in total knee arthroplasty (TKA). It is associated with high costs/economic burden and mortality. The most common cause of late PJI is due to haematogenous seedling of bacteria into the joint from remote site infection (RSI). Oral flora constitutes 6-13\% of burden in PJI. Dental interventions in patients who have undergone joint replacement surgery (JRS) are at increased risk of PJI due to bacteraemia. Dental antibiotic prophylaxes (DAP) are known to reduce this bacteraemia which in-turn may reduce the incidence of PJI. Significant controversy exists Re: the role and use of DAP in preventing PJI. This narrative review attempts to answer key questions surrounding its use based on extensive literature review in English language over past four decades.

The existing evidence is at best low and of poor quality with few comparative clinical trials that had assessed the incidence of PJI with DAP. Several systematic reviews have concluded that the existing evidence at best is inconclusive. The best existing guideline is the updated 2017 American Academy of Orthopaedic Surgeons (AAOS)-American Dental Association (ADA): Appropriate Use Criteria (AUC) that recommends shareddecision making taking individual risk factors into consideration with patients' input. DAP are recommended only in at-risk patients and is neither cost-effective nor recommended for all cases. The risk of PJI is highest in the first two years of JRS. Regular 6-12monthly dental visits, good oral hygiene and collaboration between Surgeons and Dentists facilitate providing a high quality of care thus minimizing the incidence of PJIs.
\end{abstract}

\section{Introduction}

Prosthetic joint infection (PJI) following a joint replacement surgery (JRS) for primary or secondary arthritis can be devastating and is associated with high one and five-year mortality [1]. It is the third most common cause for revision following THA (after loosening and dislocations) [2]. The economic burden on the society and costs incurred in treating it are high. Patients with PJIs have lower satisfaction with residual stiffness, pain and reduced Quality of life (QoL) [3]. PJIs are classified into few categories based on the duration from the time of index surgery. This 'duration' is interpreted differently by Microbiologists and Orthopaedic surgeons as summarized in (Table 1) [4,5]. Suffices to say that most PJIs occur within the first two years of index surgery (at $0.14 \%$ ) and the annual risk of PJI $\geq 2$ years is $0.08 \%$ for Knees [6]. Infections in acute phase are most commonly caused by Staphylococcus aureus (a normal resident on skin and nasal cavity) [7]. Methicillinresistant staphylococcus aureus (MRSA) and Methicillin-resistant staphylococcus epidermidis (MRSE) are difficult to eradicate and is a major economic burden with high morbidity [8].

Most of the late/chronic PJIs are caused by haematogenous spread of organisms from a remote site (gastro-intestinal, genitourinary, oral cavity etc...). Oral flora account for $6-13 \%$ of PJI which are potentially avoidable with preventative measures and is a modifiable risk factor [9]. Much research has focussed on this subgroup to minimize the catastrophic consequences of infection and 
use of dental antibiotic prophylaxis (DAP) has a potential role in this regard. The oral flora are largely fastidious facultative anaerobes of low virulence causing sub-clinical infections [10]. Dental interventions are associated with bacteraemia that predisposes to haematogenous spread/seedling of these organisms into the prosthetic joint [11]. Given the indolent nature and non-specific signs, such PJIs are difficult to detect in early stages. Often the microbiological culture and sensitivity studies are largely negative or dismissed as likely contaminants. With advances in microbiological diagnostics and 16s/18s RNA studies, rare organisms are cultured on prolonged incubation and enrichment media [12]. Sophisticated methods like Matrix Assisted Laser Desorption Ionization-Time of Flight: Mass Spectrometry (MALDI-TOF MS) has further enhanced the diagnostic capabilities in identifying the causative organism and facilitated strain typing in PJI [13].

Several systematic reviews have been published in the recent five years evaluating the evidence for 'DAP in preventing PJIs' [14-16]. Unfortunately these have added very little to the body of existing evidence and repeating the same message that 'Existing evidence is low and of poor quality'. A narrative review such as this is an attempt to fill this lacuna and attempts to summarize the existing evidence in one piece. It attempts to answer the following key questions with evidence-based answers:

1. What are the common oral flora and their microbiological characteristics?

2. What is the consensus on preferred antibiotic prescription prior to dental surgery?

3. How are dental procedures risk stratified and what are the risks of bacteraemia from them?

4. What is the key summary from published comparative studies Re: DAP?

5. What are the recommendation/guidelines of national professional societies Re: DAP?

6. What is the key summary from published studies on costeffectiveness with use of DAP?

\section{Methods}

The authors included a group of two Dentists (NSJ and SS) and an Orthopaedic surgeon (NSH). We undertook a comprehensive search using PubMed, MedLine, EMBASE, Google Scholar and Cochrane Review in the months from October 2020 to December 2020 (3months) with the following Medical Subject Headings (MeSH) terms: Dental procedure/intervention/surgery; Prosthetic joint infection; Prophylactic antibiotics; Hip/Knee/Shoulder/ Ankle; Joint replacement surgery; Arthroplasty; Cost-effectiveness of Prophylaxis; Professional Guidelines; Consensus position statement and downloaded all articles related to the topic of interest in an attempt to answer 'Six' key questions and summarize 'Ten' key points. We only analyzed the existing evidence published in English language over four decades (1981-2020). We specifically looked for any published White paper and professional societies position statement documents that addressed Dentists and Orthopaedic Surgeons. We also reviewed the results of surveys administered on this topic to understand the perspective of both groups (i.e. Orthopaedic surgeons and Dentists). We excluded all studies published in any language other than English given our inability in comprehending and drawing meaningful conclusions from such publications. We also excluded the role/recommendations on DAP for implants/devices other than JRS (i.e., heart valves, stents etc.).

\section{Discussion}

\section{Oral Flora \& their Microbiological Characteristics}

At least 500 organisms of different phyla inhabit the oral cavity of which $>280$ have been isolated from standard culture [9]. These are either native residents that are protective against invasion or source of dental infections (plaques, caries, gingivitis or periodontitis and dental abscess). A fine balance exists between native flora and infectious organisms. Disturbance of this balance results in plaque formation that causes breakdown of enamel. The acid production leads to teeth discolouration with cavity formation that gets colonized by bacteria. These could be either primary or secondary colonizers. The organisms on the surface are usually aerobic and those in-depths/at the core are anaerobic. Gingivitis refers to the inflammation of the gums and periodontitis is a severe form that is associated with bone loss and detachment of gums from teeth. If left untreated a dental abscess evolves. Antibiotics help in eradicating the infection/restoring the balance of oral flora. Good oral hygiene with regular dental review ensures healthy gums and early evaluation/management of plaques. The common oral flora and their microbiological characteristics are summarized in (Table 2) [17].

Table 1: Classification of prosthetic joint infection (PJI) based on duration.

\begin{tabular}{|c|c|c|}
\hline Specialty & Classification & Duration \\
\hline Microbiology Literature & ·Acute & $\leq 1$ month \\
\cline { 2 - 3 } Zimmerli, et al. 2004 [4] & -Sub-acute & $>12$ months \\
\cline { 2 - 3 } & -Chronic & $\leq 4$ weeks \\
\hline Orthopaedic Literature & -Acute & $>4$ weeks \\
\cline { 2 - 3 } & Parvizi, et al. 2016 [5] & -Chronic \\
\hline
\end{tabular}


Table 2: Common oral flora and their microbiological characteristics [10].

\begin{tabular}{|c|c|c|}
\hline Group & Gram Stain & Species \\
\hline \multirow{4}{*}{ Aerobes } & Gram positive Cocci & $\begin{array}{c}\text { Staphylococcus aureus } \\
\text { Streptococcus (pyogenic, microoccus, viridians) } \\
\text { Gemella }\end{array}$ \\
\hline & Gram negative Cocci & Moraxella \\
\hline & Gram positive bacilli & $\begin{array}{c}\text { Cornyebacterium } \\
\text { Lactobacillus }\end{array}$ \\
\hline & Gram negative bacilli & Enterobacteriaceae \\
\hline \multirow{4}{*}{ Anaerobes } & Gram positive Cocci & Peptostreptococcus \\
\hline & Gram negative Cocci & $\begin{array}{l}\text { Neisseria } \\
\text { Veilonella }\end{array}$ \\
\hline & Gram positive bacilli & Actinomyces Eubacterium \\
\hline & Gram negative bacilli & $\begin{array}{c}\text { Prevotella } \\
\text { Fusobacterium } \\
\text { Bacteroides } \\
\text { Porphyromonas }\end{array}$ \\
\hline
\end{tabular}

\section{Risk stratification of Dental Procedures \& Risk of} Bacteraemia

Dental interventions that involve cleaning, filling of cavity, manipulation of periodontal tissues, drainage of dental abscess and extraction of tooth induce bleeding have the potential to introduce bacteraemia. Simple physiological activities like brushing, vigorous flossing also induce bacteraemia to a tune of up to $50 \%$. Routine dental procedures produces 10-240 colony forming unit (CFU)/ml of blood and the bacteraemia load needed to cause PJI was at least
$1000 \mathrm{CFU} / \mathrm{ml}$ [18]. Bacteraemia is merely a surrogate measure and there exists no direct evidence linking it to PJI. Some experts believed the prosthetic joints are to some degree protected by fibrotic scar and capsule from circulating less virulent oral flora. These interventions are classified as either low or high-risk procedures based on the severity of bacteraemia and (Table 3) summarizes such procedures along with percentage of bacteraemia load [19]. It is evident periodontal procedures and dental implantology/ extractions are associated with significant bacteraemia and constitute 'high risk' for haematogenous dissemination.

Table 3: Low vs. High-risk dental procedures [11,19].

\begin{tabular}{|c|c|c|}
\hline Risk Strategy & Procedure & Percentage of Bacteraemia \\
\hline \multirow{3}{*}{ Physiological activity } & -Tooth brushing & $0-25 \%$ \\
\hline & -Chewing & $17-50 \%$ \\
\hline & $\cdot$ Flossing & $\geq 50 \%$ \\
\hline \multirow{3}{*}{ Low risk procedures } & -Intra-canalicular endodontic Rx & $0-30 \%$ \\
\hline & -Scaling/cleaning and inter-dental cleaning with dental probe & $8-80 \%$ \\
\hline & -Irrigation and other minor procedures (filling etc...) & $7-50 \%$ \\
\hline \multirow{4}{*}{ High risk procedures } & -Single tooth extraction & $\geq 50 \%$ \\
\hline & -Multiple teeth extraction & $\geq 68 \%$ \\
\hline & - Extra-canalicular endodontic Rx/procedures beyond tooth apex & $0-54 \%$ \\
\hline & - Periodontal / Flap surgery, Dental Implantology and gingivectomy etc... & $\geq 83 \%$ \\
\hline
\end{tabular}

\section{Antibiotic Susceptibility Pattern of Oral Flora}

The infections from oral flora are usually treated by empirical antibiotics in the first instance. They are usually sensitive to $\beta$-Lactam Penicillins (i.e., Ampicillin and Amoxicillin) and Cephalosporins (i.e., first generation agents-Cephalexin and Cephradine). They are bactericidal and act by inhibiting the cell wall formation. Clindamycin is the preferred antibiotic in patients who are allergic to Penicillin and is bacteriostatic. Amoxicillin reduces the risk of oral bacteraemia from $63 \%$ to $35 \%$ in one of the studies and Erythromycin was used in 1980s [20]. Most publications recommend a single dose administered an hour prior to dental procedure with few proposing $24 \mathrm{hr}$ cover in severe infections/ 
extensive surgery. Key class of patients who had the highest benefit from DAP were:

i) On immunosuppressive therapy

ii) Dermatological infection and iii) Obvious focal infection (i.e., Urosepsis etc.).

Table 4 summarizes preferred DAP to be used when a decision is made to administer one [19].

Table 4: Summary of dental antibiotic prophylaxis (DAP) of choice for procedures [19].

\begin{tabular}{|l|c|}
\hline \multirow{2}{*}{ No Penicillin allergy } & 1 \\
\cline { 2 - 2 } & Ampicillin-2gm po/im/iv \\
\cline { 2 - 2 } & Amoxicillin \& Clavulanate-625mg po/iv \\
\cline { 2 - 2 } Penicillin allergy present & Cefazolin-1gm iv (if unable to have orally) \\
\cline { 2 - 2 } & Clindamycin 600mg po \\
\hline \multirow{2}{*}{ Clindamycin $600 \mathrm{mg}$ iv (if unable to have orally) }
\end{tabular}

§Add Metronidazole $400 \mathrm{mg}$ po (or 500mg IV if unable to have orally) for extended $\mathrm{Gm}$-ve cover.

\section{Published Comparative Studies (LoE II \& III)}

Five comparative studies have been published evaluating PJI in patients undergoing dental procedures since 1986 (Table 5) [21-25]. with the most recent study involving a large cohort of 255,568 Taiwanese patients undergoing THA or TKA over 12years by Kao, et al. [25]. The sub-set of dental cohort was 57,066 patients and the number of PJI was 328 (incidence of $0.57 \%$ ). This was retrospectively matched to a cohort of 348 non-dental PJI (incidence of $0.61 \%$ ) accounting for all confounding factors and had robust research methodology. They found no correlation between PJI and dental intervention ( $\mathrm{p}=0.31$ ). They did not recommend any DAP and recommended shared decision-making seeking patients input along the lines of AAOS-ADA: AUC [26]. This remains the largest sample size to date amongst all published studies and was retrospective (i.e. Level of evidence [LoE] III). The best available highest LoE study is that of Berbari, et al. [22] from 2010 that involved a prospective comparative 1:1 matched review (i.e., LoE II) in a cohort of 339 PJI (THA and TKA) in patients who had dental procedures within the 6months and 2years following index surgery who had no dental intervention [22]. They found no correlation for Low vs. High-risk procedures and with or without DAP. They concluded dental procedures not to be a risk factor for subsequent PJI and that administration of DAP did not reduce the risk of PJI.

Table 5: Summary of comparative studies evaluating the role of prophylactic antibiotics and prevention of prosthetic joint infections (PJI).

\begin{tabular}{|c|c|c|c|c|c|}
\hline $\begin{array}{l}\text { Study } \\
\text { name }\end{array}$ & Study design & LoE & $\begin{array}{l}\text { Confounding factors account- } \\
\text { ed }\end{array}$ & Results of the study & Comments \\
\hline $\begin{array}{c}\text { Jacobson } \\
\text { et al, } 1986 \\
{[21]}\end{array}$ & $\begin{array}{l}\text { First reported nested case } \\
\text { control study spanning } 13 y \\
\text { (1970-83). Three patients } \\
\text { developed PJI. }\end{array}$ & III & $\begin{array}{l}\text { Confounding factors (age, } \\
\text { smoking status etc...) were not } \\
\text { accounted for. }\end{array}$ & $\begin{array}{l}\text { Strong evidence against } \\
\text { association between } \\
\text { dental procedures and } \\
\text { PJI. }\end{array}$ & $\begin{array}{l}\text { The results implied that dental } \\
\text { procedures were associated with } \\
\text { protection from PJI and some ambi- } \\
\text { guity with ' } \boldsymbol{p} \text { ' value. }\end{array}$ \\
\hline $\begin{array}{c}\text { Berbari et } \\
\text { al, } 2010 \\
\text { [22] }\end{array}$ & $\begin{array}{l}\text { Case control study evaluat- } \\
\text { ing low vs. high risk dental } \\
\text { procedures undertaken } \\
\text { with / without prophylactic } \\
\text { antibiotics. }\end{array}$ & II & $\begin{array}{l}\text { Paired matching accounting for } \\
\text { confounding factors was not } \\
\text { undertaken, but power analysis } \\
\text { with frequency matching was } \\
\text { performed. Other medical } \\
\text { co-morbidities (DM, CKD etc.) } \\
\text { were matched. }\end{array}$ & $\begin{array}{l}\text { No association between } \\
\text { dental procedures and } \\
\text { development of PJI. The } \\
\text { CI was wide and their } \\
\text { findings were consistent } \\
\text { with other published } \\
\text { studies. }\end{array}$ & $\begin{array}{l}\text { Excellent study that started with } \\
\text { outcomes and followed retrospec- } \\
\text { tively assessing for differences in } \\
\text { exposure. Robust methodology } \\
\text { relying on review of dental records } \\
\text { rather than patients' recollection. } \\
\text { Very good study for evaluating rare } \\
\text { outcomes such as PJI. }\end{array}$ \\
\hline $\begin{array}{c}\text { Skaar et al, } \\
2011 \text { [23] }\end{array}$ & $\begin{array}{l}\text { Nested case-control study of } \\
\text { Medicare patient database } \\
\text { over } 10 \mathrm{y} .\end{array}$ & III & $\begin{array}{l}\text { 3:1 ratios of controls vs. case } \\
\text { match for age, sex and con- } \\
\text { founding factors. }\end{array}$ & $\begin{array}{l}\text { No association between } \\
\text { dental procedures and } \\
\text { PJI. }\end{array}$ & $\begin{array}{c}\text { Good methodology and reporting } \\
\text { of hazard ratio (HR) and Odds ratio } \\
\text { (OR). The CI was wide and ' } \boldsymbol{p} \text { ' value } \\
\text { showed extremely weak evidence } \\
\text { against the null hypothesis. }\end{array}$ \\
\hline $\begin{array}{l}\text { Swan et al, } \\
2011 \text { [24] }\end{array}$ & $\begin{array}{l}\text { Nested case-control study } \\
\text { reporting sentinel events } \\
\text { associated with PJI. }\end{array}$ & III & $\begin{array}{l}17 \text { PJI matched with } 51 \text { controls } \\
\text { in 1:3 ratio. But the controls } \\
\text { were not from the same data- } \\
\text { base, geographical location or } \\
\text { socio-economic strata (het- } \\
\text { erogeneity in the two groups } \\
\text { present). }\end{array}$ & $\begin{array}{l}\text { Patients with cellulitis } \\
\text { and } \geq 4 \text { co-morbidities @ } \\
\text { risk of developing PJI. }\end{array}$ & $\begin{array}{l}\text { Wide CI and many methodological } \\
\text { / statistical shortcomings make the } \\
\text { results unreliable. }\end{array}$ \\
\hline $\begin{array}{l}\text { Kao et al, } \\
2017 \text { [25] }\end{array}$ & $\begin{array}{c}\text { Retrospective nested } \\
\text { case-control study from } \\
\text { Taiwan over } 12 \mathrm{y} \text { involving } \\
57,000 \text { patients }\end{array}$ & III & $\begin{array}{c}\text { Large sample size of } 328 \text { vs. } 348 \\
\text { dental and non-dental cohorts } \\
\text { of patients with PJI with } 1: 1 \\
\text { matching. }\end{array}$ & $\begin{array}{l}\text { No association between } \\
\text { dental procedure and } \\
\text { prophylactic antibiotics } \\
\text { on PJI (i.e. the infection } \\
\text { rate was similar in both } \\
\text { groups). }\end{array}$ & $\begin{array}{l}\text { Most recent publication with } \\
\text { impressive sample size and robust } \\
\text { methodology. Multivariate analysis } \\
\text { was also undertaken. }\end{array}$ \\
\hline
\end{tabular}


Couple of LoE III studies were published in 2011 by Skaar, et al. and Swan, et al. [23, 24]. Skaar observed 42 PJI in all JRS over 10years and case matched it 126 controls (1:3 ratio) [23]. They found no association between dental procedures and PJI. Patient profile risk factors that strongly correlated with PJI observed in literature were:

i) Morbid obesity

ii) Alcohol and nicotine

iii) Male sex

iv) Age $>65$ years

v) Operative time of $>2$ hours

vi) Diabetes mellitus and

vii) Rheumatoid arthritis (and immunosuppressed states).

Swan, et al. [24] observed 17 late PJI in a cohort of 1641 patients who underwent TKA. 15 PJIs were preceded by a sentinel event and only one patient had a dental source [24].

\section{Published Recommendations of National Professional Societies}

The professional Dentist and Orthopaedic scientific societies have jointly produced guidelines and recommended position statements regarding DAP in patients with prosthetic joints undergoing dental procedures and is summarized in (Table 6) [2636]. Despite best efforts and exhaustive review of literature, there is little consensus from these regulatory bodies regarding best practice. As bacteraemia was only an indirect surrogate marker for PJI, it was felt prophylactic antibiotics was not required. Australia along with European Union countries notably France, Netherlands, Sweden and Switzerland have also recommended against routine use of DAP [26-31]. This argument held ground and was also accepted by British orthopaedic association (BOA) and British dental association (BDA) [32,33]. The American association of orthopaedic surgeons (AAOS) and American dental association (ADA) did not recommend antibiotic proplylaxis in 2003 [34]. However the AAOS unilaterally made a decision in 2009 to strongly consider/ administer DAP in all patients with prosthetic joints with Amoxycillin [35]. In-summary the AAOS and ADA have gone back and forth reviewing and revising the recommendations on no less than three occasions over the past fifteen years [34-36]. The 2009 recommendation of the AAOS was strongly criticised by the Council of Scientific Affairs (CSA) of ADA who published a comprehensive evidence-based practice recommendation and found no evidence to support routine DAP [37]. The AAOS and ADA began working jointly to address this issue and came up with appropriate use criteria (AUC) in 2017 and was developed by Delphi consensus evaluating 64 scenarios [38]. The five key determinants of AUC were:

Table 6: Summary of published recommendations from national bodies, their guidelines with respect to the use of prophylactic antibiotics.

\begin{tabular}{|c|c|c|c|}
\hline Country & References & Prophylactic antibiotics & Comments \\
\hline Australia & $\begin{array}{l}\text { Scott et al, } 2005 \\
{[26]}\end{array}$ & Recommended & $\begin{array}{l}\text { High risk dental procedures esp. in immunocompromised patients should be under- } \\
\text { taken under the cover of prophylactic antibiotics. }\end{array}$ \\
\hline France & $\begin{array}{l}\text { Legout et al } \\
2012[27]\end{array}$ & Not Recommended & Narrative review: Recommends against routine use of prophylactic antibiotics. \\
\hline Netherlands & $\begin{array}{l}\text { Rademacher et } \\
\text { al } 2017 \text { [28] }\end{array}$ & Not Recommended & Systematic review: Recommends against routine use of prophylactic antibiotics. \\
\hline Sweden & $\begin{array}{l}\text { Blomgren et al, } \\
2009 \text { [29] }\end{array}$ & Not Recommended & $\begin{array}{l}\text { Not recommended in healthy patients with no risk factors having a prosthetic joint. } \\
\text { Recommends shared decision-making in immunocompromised and patients with risk } \\
\text { factors. }\end{array}$ \\
\hline Switzerland & $\begin{array}{l}\text { Rossi et al, } 2007 \\
\qquad 30]\end{array}$ & Recommended & $\begin{array}{c}\text { Recommended in patients undergoing dental procedures if within } 12 \text { months from } \\
\text { the date of surgery. The guideline does not specify in immuncompromised / high risk } \\
\text { patients. }\end{array}$ \\
\hline \multirow{2}{*}{$\begin{array}{l}\text { United King- } \\
\text { dom }\end{array}$} & $\begin{array}{l}\text { Simmons et al } \\
1992[32]\end{array}$ & Not Recommended & $\begin{array}{l}\text { Prophylactic antibiotics are of no additional value / benefit. It does not mention in } \\
\text { high risk / immunocompromised patients. }\end{array}$ \\
\hline & $\begin{array}{l}\text { Seymour et al } \\
2003[33]\end{array}$ & Recommended & $\begin{array}{l}\text { Recommends prophylactic antibiotics in patient with Diabetes Mellitus, Rheumatoid } \\
\text { arthritis, Hemophilia, Malignancy, Overt oral sepsis / complex dental work ( }>45 \mathrm{~m}) \text {. }\end{array}$ \\
\hline \multirow{3}{*}{$\begin{array}{l}\text { United States } \\
\text { of America }\end{array}$} & $\begin{array}{l}\text { AAOS / ADA } \\
2003[34]\end{array}$ & Not Recommended & $\begin{array}{l}\text { All high-risk procedures carried within 2years from the date of hip / knee arthroplas- } \\
\text { ty should be performed under the cover of prophylactic antibiotics. } \\
\text { Select cohort of patients (Radiotherapy / Immunocompromised / Malignancy / Diabe- } \\
\text { tes mellitus / Sickle cell disease / Asplenism etc...) should be covered with prophylac- } \\
\text { tic antibiotics > 2years following hip / knee arthroplasty. }\end{array}$ \\
\hline & ADA 2009 [35] & Recommended & $\begin{array}{l}\text { All patients with prosthetic joints (hips and knees) need prophylactic antibiotics } \\
\text { following dental procedures as it causes significant bacteremia. }\end{array}$ \\
\hline & $\begin{array}{l}\text { AAOS / ADA } \\
2012-13[36]\end{array}$ & Not Recommended & $\begin{array}{l}\text { Involves patients in shared decision-making and recommends the AUC (Appropriate } \\
\text { use criteria) to ascertaining prescription of prophylactic antibiotics. Encourages col- } \\
\text { laboration between dentists and primary care physicians and antibiotic cover on case } \\
\text { by case / individualized basis. }\end{array}$ \\
\hline
\end{tabular}


viii) Nature of underlying procedure

ix) Immunocompromised status of the patient

x) Presence of Diabetes mellitus

xi) Previous h/o PJI needing surgery and

xii) Planned dental procedure $<12$ months from primary surgery.

Prophylactic antibiotics was not indicated in $61 \%$ and considered appropriate in only $12 \%$ of scenarios. The degree of consensus also varied from high (score of 7-9), maybe (score of 4-6) and low (score of 1-3). More recently, the AAOS also published a decision-making tree to simplify things and ascertain where DAP was appropriate [39].

\section{Published Cost-effectiveness Studies}

Economic modelling and cost-effectiveness studies are increasingly conducted since 2010 onwards to justify therapeutic intervention and seek insurance authorization. These are least common types of studies reported in Orthopaedic literature accounting for $<2 \%$ of all publications. Four key studies have reported on Risk vs. Benefit and cost-effectiveness with routine use of DAP and their key findings are summarized in (Table 7) [4043]. The life-time risk of PJI is $\leq 2.0 \%$ and oral pathogens account for $6-13 \%$ of all PJIs. The number of patients who will need to be administered antibiotics before dental procedures to prevent one PJI is 625-1250. Such a blanket administration of antibiotics carries a risk of adverse event, intolerance or anaphylactic reaction in at least 37-80 patients for Amoxicillin alone. Penicillin is responsible for $75 \%$ of fatal anaphylaxis in the USA [44]. Dentists are the highest prescribers of Clindamycin amongst healthcare professionals and carried highest risk (odds ratio [OR] of 17-20) [45]. Its use risks causing Clostridium difficile infections (CDI) and annually 24,000 deaths are attributed to CDI alone. A single dose of $600 \mathrm{mg}$ Clindamycin could potentially cause 12 deaths/million due to CDI and Orthopaedic surgeons were unaware of this fact [46]. The DAP would only be cost-effective if the risk of HPJI was $\geq 0.7 \%$ and current best estimate/projections of PJI from oral flora was at best $0.03-0.10 \%$.

Table 7: Summary of published cost-effectiveness studies on dental antibiotic prophylaxis.

\begin{tabular}{|c|c|c|}
\hline Publication \& Citation & Study design & Conclusion and Key message \\
\hline $\begin{array}{l}\text { Lockhart et al } \\
\qquad \begin{array}{l}\text { (2013) } \\
{[40]}\end{array}\end{array}$ & $\begin{array}{l}\text { Predicted cost-effectiveness from preva- } \\
\text { lence studies involving } 15 \text { conditions. }\end{array}$ & $\begin{array}{l}\text { Incurs cost of up to } \$ 15 \text { million with no proven benefit and additional risk } \\
\text { of adverse events (incl. C. Difficile induced diarrheal deaths). }\end{array}$ \\
\hline $\begin{array}{c}\text { Slover et al } \\
\qquad 2015) \\
{[41]}\end{array}$ & $\begin{array}{l}\text { Decision model to evaluate the cost-ef- } \\
\text { fectiveness of DAP from payer perspec- } \\
\text { tive. }\end{array}$ & $\begin{array}{l}\text { Estimated average cost incurred from complications of antibiotics per } \\
\text { prescription was } \$ 14.30 \text {. The minimum threshold incidence of PJI was } \\
\qquad 0.75 \% \text { to justify DAP. }\end{array}$ \\
\hline $\begin{array}{l}\text { Skaar et al } \\
\text { (2018) } \\
{[42]}\end{array}$ & $\begin{array}{l}\text { Cost-effectiveness decision model using } \\
\text { Markov analysis }\end{array}$ & $\begin{array}{l}\text { Questions / discourages the blanket policy of using prophylactic antibiot- } \\
\text { ics in all cases. Recommends use of antibiotics in at-risk patient popula- } \\
\text { tion. }\end{array}$ \\
\hline $\begin{array}{l}\text { Stanley et al } \\
\text { (2020) } \\
{[43]}\end{array}$ & $\begin{array}{l}\text { Osteoarthritis policy model with comput- } \\
\text { er simulation of knee OA evaluating costs } \\
\text { with Quality adjusted life expectancy } \\
\text { (QALE) in Type II DM. }\end{array}$ & $\begin{array}{l}\text { Incremental cost effectiveness ratio (ICER) of } \$ 66,000 / \text { Quality-adjusted } \\
\text { life years(QALY). Antibiotic prophylaxis was cost-effective in } 58 \% \text { of sce- } \\
\text { narios with willingness to pay threshold of } \$ 100,000 \text {. }\end{array}$ \\
\hline
\end{tabular}

All published studies in Table 7 have rightfully questioned the routine use of DAP as did not prevent PJIs. Most recently study by Stanley et al in 2020 found that DAP was cost-effective in only $32 \%$ of scenarios with willingness to pay threshold of $\geq \$ 50,000$ in select group of patients with Type II Diabetes Mellitus [43]. Skaar et al. recommended DAP in highly select group of 'at-risk' patients:

i) On renal dialysis

ii) Solid organ transplant (on immunosuppressive medication)

iii) Diabetes and Rheumatoid arthritis and

iv) Poor oral hygiene and severe periodontal disease [42].
Their Value of Information (VoI) projected cost estimate of $\$ 80 \mathrm{~m}$ at an estimate of 700,000 TKA/year over 5-year time horizon.

\section{Conclusion}

The three components of evidence-based practice (EBP) includes:

i) Scientific evidence

ii) Clinical experience and

iii) Patient values

Professional judgement coupled with patients' preferences and backed by EBP is needed for optimal treatment of PJIs. Surgeon 
vs. Dentist surveys from New Zealand, Australia and Canada observed that a majority of surgeons preferred to err on the side of administration of DAP despite existing evidence relying on practice experience and opinion papers (LoE V) [47-49]. Orthopaedic surgeons are concerned about PJI against a background of dental interventions and prefer to prescribe DAP as they see high value and low risk with it. Dentists exercise more discretion seeing this approach to be associated with low value and high risk of adverse effects. Patients are struck in the middle and are in a conundrum. We hope this article addresses this dilemma summarizing the existing evidence. $75 \%$ of the Dentists and $88 \%$ of Orthopaedic surgeons still prescribed DAP citing 'Defensive Practice' as the reason fearing lawsuit and allegations of negligence.

A recent survey found none of the 28 professionals (20 Dentists and 8 Orthopaedic surgeons) used AAOS-ADA risk calculator to aid them in decision-making re: DAP prescription. It is reasonable to adhere with AAOS-ADA: AUC guidelines and we strongly recommend incorporating it as a part of one's practice. Dialogue between Surgeons, Dentists and patients in shared decisionmaking and need for 'Dental Stewardship' is proposed [50]. The AAOS-ADA: AUC decision tree represented pictorially in (Figure 1) aids in simplified decision-making [39].

We would refrain from administering antibiotics esp. if patients are immunocompetent or have minimal medical co-morbidities (Charleston index $\leq 4$ ). Maintaining good oral hygiene and regular 6-12monthly dental assessments (i.e., enhanced preventive strategies) are believed to reduce the risk of PJI by $\geq 30 \%$. Suffices to say that the existing evidence for using DAP in preventing PJI is weak and level of recommendation is at best ' $\mathrm{C}$ '. Additional systematic reviews will be of very little benefit to the existing evidence.

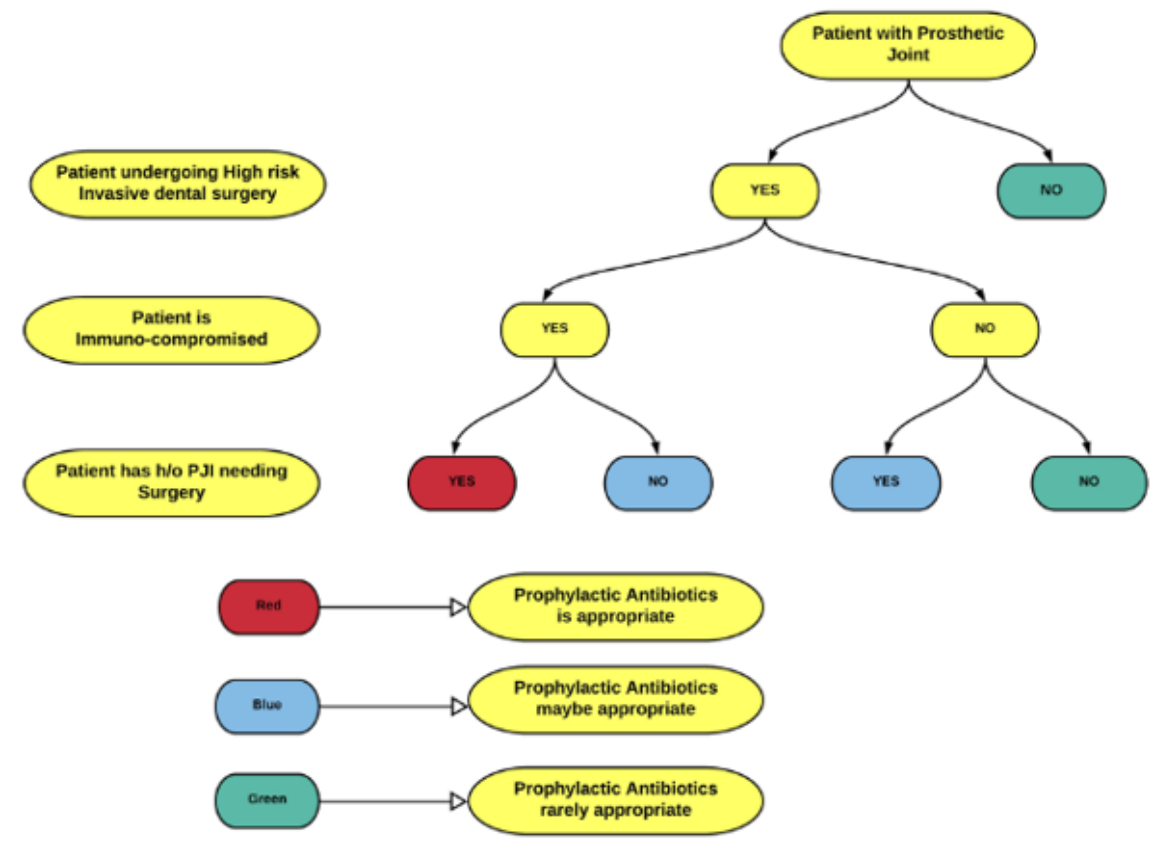

Figure 1: AAOS-ADA Decison tree explained pictorially.

\section{Summary: Top Ten Key Points}

1. In-addition to the existing evidence being low and of poor quality for use of DAP, a LoE I study (i.e., Randomized controlled trial) may be impractical/not feasible given several variables/ confounding factors and is unlikely to happen in the foreseeable future.

2. Oral pathogens are responsible for $6-13 \%$ of PJIs and are difficult to culture often needing enrichment media and prolonged incubation.

3. The risk of PJIs is high in the first two years of index/ primary surgery and Orthopaedic surgeons who were inpractice for $>15 y$ prescribed it most often than junior colleagues.
4. The incidence of PJI from dental interventions is due to bacteraemia that is only a 'surrogate marker' and at best an 'indirect association'.

5. Dental procedures are classified as 'Low vs. High risk' interventions. Routine use of DAP for low risk procedures in healthy patients is not recommended.

6. 'At-risk' group of patients undergoing high risk procedures should be performed under prophylactic antibiotics cover.

7. Difference of opinion exists between Dentists and Orthopaedic surgeons Re: DAP. Orthopaedic specialists prescribed antibiotics more often independent of the nature of dental procedure whilst Dentists exercised more discretion in their prescriptions. 
8. National recommendations differed widely and were mainly from Europe and North American countries. There were little/no guidelines from Asian (including India) and African countries.

9. Shared decision-making involving patients and their preferences guided by AAOS-ADA: AUC is the best available evidence at present to guide healthcare professionals Re: DAP.

10. DAP are neither cost-effective economically nor shown to be better with regards to 'Benefit vs. Risk' ratio when adverse events with their use was taken into consideration.

\section{Acknowledgement}

Mr. M Sarungi \& Mr. M Changulani, Orthopaedic Surgeons: U.K.

\section{Conflict of Interest}

All authors do not have any CoI to disclose and no funding from any source was received by any of us for this research.

\section{References}

1. Zmistowski B, Karam JA, Durinka JB, Casper DS, Parvizi J (2013) Periprosthetic joint infection increases the risk of one-year mortality. J Bone Joint Surg Am 95(24): 2177-2184.

2. Sadoghi P, Liebensteiner M, Agreiter M, Leithner A, Bohler N, et al (2013) Revision surgery after total joint arthroplasty: a complicationbased analysis using worldwide arthroplasty registers. J Arthroplasty 28(8): 1329-1332.

3. Ethgen O, Bruyere O, Richy F, Dardennes C, Reginster JY (2004) Healthrelated quality of life in total hip and total knee arthroplasty. A qualitative and systematic review of the literature. J Bone Joint Surg Am 86(5): 963974.

4. Zimmerli W, Trampuz, A, Ochsner PE (2004) Prosthetic-joint infections. N Engl J Med 351(16): 1645-1654.

5. Parvizi J, Fassihi SC, Enayatollahi MA (2016) Diagnosis of Periprosthetic Joint Infection Following Hip and Knee Arthroplasty. Orthop Clin North Am 47(3): 505-515.

6. Huotari K, Peltola M, Jämsen E (2015) The incidence of late prosthetic joint infections: a registry-based study of 112,708 primary hip and knee replacements. Acta Orthop 86(3): 321-325.

7. Kapadia BH, Berg RA, Daley JA, Fritz J, Bhave A, et al. (2016) Periprosthetic joint infection. Lancet 387(10016): 386-394.

8. Parvizi J, Azzam K, Ghanem E, Austin MS, Rothman RH (2009) Periprosthetic infection due to resistant staphylococci: serious problems on the horizon. Clin Orthop Relat Res 467(7): 1732-1739.

9. Young H, Hirsh J, Hammerberg EM, Price CS (2014) Dental disease and periprosthetic joint infection. J Bone Joint Surg Am 96(2): 162-168.

10. Reynolds-Campbell G, Nicholson A, Thoms-Rodriguez CA (2017) Oral Bacterial Infections: Diagnosis and Management. Dent Clin North Am 61(2): 305-318.

11. Hall G, Heimdahl A, Nord C E (1999) Bacteremia after oral surgery and antibiotic prophylaxis for endocarditis. Clin Infect Dis 29(1): 1-8; quiz 9-10.

12. Mitreva M (2017) The Microbiome in Infectious Diseases. In J Cohen, WG Powderly, SM Opal (Eds.), Infectious Diseases (4th Edn.), p: 68-74

13. Singhal N, Kumar M, Kanaujia PK, Virdi JS (2015) MALDI-TOF mass spectrometry: an emerging technology for microbial identification and diagnosis. Frontiers in microbiology 6: 791.

14. Rademacher WMH, Walenkamp GHIM, Moojen DJF, Hendriks JGE, Goedendorp TA, et al. (2017) Antibiotic prophylaxis is not indicated prior to dental procedures for prevention of periprosthetic joint infections. Acta orthopaedica 88(5): 568-574.

15. Slullitel PA, Oñativia JI, Piuzzi NS, Higuera-Rueda C, Parvizi J, et al. (2020) Is there a Role for Antibiotic Prophylaxis Prior to Dental Procedures in Patients with Total Joint Arthroplasty? A Systematic Review of the Literature. J Bone Joint Infect 5(1): 7-15.

16. Moreira AI, Mendes L, Pereira JA (2020) Is there scientific evidence to support antibiotic prophylaxis in patients with periodontal disease as a means to decrease the risk of prosthetic joint infections? A systematic review. Int Orthop 44(2): 231-236.

17. Levi ME, Eusterman VD (2011) Oral infections and antibiotic therapy. Otolaryngol Clin North Am 44(1): 57-78.

18. Fernandez-Sampedro M, Salas-Venero C, Fariñas Álvarez C, Sumillera M Pérez-Carro L, et al. (2015) 26Postoperative diagnosis and outcome in patients with revision arthroplasty for aseptic loosening. BMC infectious diseases 15: 232

19. Kotze, MJ (2009) Prosthetic joint infection, dental treatment and antibiotic prophylaxis. Orthop Rev (Pavia) 1(1): e7.

20. Coulter WA, Coffey A, Saunders ID, Emmerson AM (1990) Bacteremia in children following dental extraction. J Dent Res 69(10): 1691-1695.

21. Jacobson JJ, Millard HD, Plezia R, Blankenship JR (1986) Dental treatment and late prosthetic joint infections. Oral Surg Oral Med Oral Pathol 61(4): 413-417.

22. Berbari EF, Osmon DR, Carr A, Hanssen AD, Baddour LM, et al. (2010) Dental procedures as risk factors for prosthetic hip or knee infection: a hospital-based prospective case-control study. Clin Infect Dis 50(1): 8-16.

23. Skaar DD, O'Connor H, Hodges JS, Michalowicz BS (2011) Dental procedures and subsequent prosthetic joint infections: findings from the Medicare Current Beneficiary Survey. J Am Dent Assoc 142(12): 13431351.

24. Swan J, Dowsey M, Babazadeh S, Mandaleson A, Choong PFM (2011) Significance of sentinel infective events in haematogenous prosthetic knee infections. ANZ Journal of Surgery 81(1-2): 40-45.

25. Kao FC, Hsu YC, Chen WH, Lin JN, Lo YY, et al. (2017) Prosthetic Joint Infection Following Invasive Dental Procedures and Antibiotic Prophylaxis in Patients with Hip or Knee Arthroplasty. Infect Control Hosp Epidemiol 38(2): 154-161.

26. Scott JF, Morgan D, Avent M, Graves S, Goss AN (2005) Patients with artificial joints: do they need antibiotic cover for dental treatment? Aust Dent J 50(4 Suppl 2): S45-53.

27. Legout L, Beltrand E, Migaud H, Senneville E (2012) Antibiotic prophylaxis to reduce the risk of joint implant contamination during dental surgery seems unnecessary. Orthop Traumatol Surg Res 98(8): 910-914.

28. Rademacher WMH, Walenkamp GHIM, Moojen DJF, Hendriks JGE, Goedendorp TA, et al. (2017) Antibiotic prophylaxis is not indicated prior to dental procedures for prevention of periprosthetic joint infections. Acta orthopaedica 88(5): 568-574.

29. Blomgren J, Heimdahl A, Struwe J (2009) [Antibiotic prophylaxis seldom indicated in dental care: important that physicians and dentists agree]. Lakartidningen 106(52): 3485-3486.

30. Rossi M, Zimmerli W, Furrer H, Zanetti G, Mühlemann K, Täuber MG (2005) [Antibiotic prophylaxis for late blood-borne infections of joint prostheses]. Schweiz Monatsschr Zahnmed 115(6): 571-579.

31. Alao U, Pydisetty R, Sandiford NA (2015) Antibiotic prophylaxis during dental procedures in patients with in situ lower limb prosthetic joints. Eur J Orthop Surg Traumatol: 25(2): 217-220.

32. Simmons NA, Ball AP, Cawson RA, Eykyn SJ, Hughes SP, et al. (1992) Case against antibiotic prophylaxis for dental treatment of patients with joint prostheses. Lancet 339(8788): 301 
33. Seymour RA, Whitworth JM, Martin M (2003) Antibiotic prophylaxis for patients with joint prostheses-still a dilemma for dental practitioners. Br Dent J 194(12): 649-653.

34. American Dental Association (2003) Antibiotic prophylaxis for dental patients with total joint replacements. J Am Dent Assoc 134(7): 895-899.

35. Jevsevar DS, Abt E (2013) The new AAOS-ADA clinical practice guideline on Prevention of Orthopaedic Implant Infection in Patients Undergoing Dental Procedures. J Am Acad Orthop Surg 21(3): 195-197.

36. (2021) https://www.orthoguidelines.org/go/auc/default.cfm?auc id=224995\&actionxm=Terms/.

37. Quinn RH, Murray JN, Pezold R, Sevarino KS (2017) Management of Patients with Orthopaedic Implants Undergoing Dental Procedures. J Am Acad Orthop Surg 25(7): e138-141.

38. Sollecito TP, Abt E, Lockhart PB, Truelove E, Paumier TM, et al. (2015) The use of prophylactic antibiotics prior to dental procedures in patients with prosthetic joints: Evidence-based clinical practice guideline for dental practitioners--a report of the American Dental Association Council on Scientific Affairs. J Am Dent Assoc 146(1): 11-16 e18.

39. (2021) https://www.aaos.org/aaosnow/2020/mar/qualityresearch/ quality-research02/.

40. Lockhart PB, Blizzard J, Maslow AL, Brennan MT, Sasser H, et al. (2013) Drug cost implications for antibiotic prophylaxis for dental procedures. Oral Surg Oral Med Oral Pathol Oral Radiol 115(3): 345-353.

41. Slover JD, Phillips MS, Iorio R, Bosco J (2015) Is routine antibiotic prophylaxis cost effective for total joint replacement patients? J Arthroplasty 30(4): 543-546.

42. Skaar DD, Park T, Swiontkowski MF, Kuntz KM (2018) Is Antibiotic Prophylaxis Cost-effective for Dental Patients Following Total Knee Arthroplasty? JDR Clinical \& Translational Research 4(1): 9-18.
43. Stanley EE, Trentadue TP, Smith KC, Sullivan JK, Thornhill TS, et al. (2020) Cost-effectiveness of dental antibiotic prophylaxis in total knee arthroplasty recipients with type II diabetes mellitus. Osteoarthritis and Cartilage Open 2(4): 100084.

44. Swift JQ Gulden WS (2002) Antibiotic therapy--managing odontogenic infections. Dent Clin North Am 46(4): 623-633.

45. Durkin MJ, Hsueh K, Sallah YH, Feng Q, Jafarzadeh SR, et al. (2017) An evaluation of dental antibiotic prescribing practices in the United States. J Am Dent Assoc 148(12): 878-886.e1.

46. Goff DA, Mangino JE, Glassman AH, Goff D, Larsen P, et al. (2019) Review of Guidelines for Dental Antibiotic Prophylaxis for Prevention of Endocarditis and Prosthetic Joint Infections and Need for Dental Stewardship. Clin Infect Dis 71(2): 455-462.

47. Tong D, Theis JC (2008) Antibiotic prophylaxis and invasive dental treatment in prosthetic joint patients. N Z Med J 121(1280): 45-52.

48. McNally CM, Visvanathan R, Liberali S, Adams R J (2016) Antibiotic prophylaxis for dental treatment after prosthetic joint replacement: exploring the orthopaedic surgeon's opinion. Arthroplasty Today 2(3): 123-126.

49. Colterjohn T, de Beer J, Petruccelli D, Zabtia N, Winemaker M (2014) Antibiotic Prophylaxis for Dental Procedures at Risk of Causing Bacteremia Among Post-Total Joint Arthroplasty Patients: A Survey of Canadian Orthopaedic Surgeons and Dental Surgeons. J Arthroplasty 29(6): 1091-1097.

50. Lockhart PB, Thornhill MH, Zhao J, Baddour LM, Davis J, et al. (2020) Prophylactic antibiotic prescribing in dental practice: Findings from a National Dental Practice-Based Research Network questionnaire. J Am Dent Assoc 151(10): 770-781. 